\title{
Integration of Solid Waste Management Policies in Kenya: Analysis of Coherence, Gaps and Overlaps
}

\author{
Tilahun Nigatu Haregu ${ }^{1}$, Abdhalah K. Ziraba² and Blessing Mberu ${ }^{3}$ \\ African Population and Health Research Center \\ P.O. Box 10787-00100 \\ APHRC Campus, Kitisuru \\ Nairobi, Kenya \\ tharegu@aphrc.org
}

\begin{abstract}
This study examined the extent to which current solid waste management policies in Kenya are integrated, particularly as they addressed associated health challenges among vulnerable urban populations. The study was a critical interpretive synthesis of contents of the existing policies on solid waste management. We examined horizontal, vertical, and diagonal policy integration as well as internal and external integration. While general solid waste management policies are broad, the institutional and implementation mechanisms proposed by these policies are more centralized. The sector-specific and embedded policies are coherent with the overall theme of the policy document they are in, but they lack mechanisms of implementation within the same policy framework. Major gaps exist in stipulating clear policy strategies and implementation mechanisms as they address health outcomes. Overall, existing solid waste management policies clearly state the policy directions in terms of the required outcomes. But explicit articulation of policy strategies and implementation mechanisms is inadequate.
\end{abstract}

Keywords: Policy integration, solid waste management, Kenya

\section{Introduction}

With the urban population in Kenya estimated to be growing at a rate higher than that of the country's general population, waste generation and management will remain a major challenge. The industrialization and urbanization in the country dominated by one major city (Nairobi), about four times bigger than the next largest urban Centre (Mombasa), has led to an exponential increase in the generation of solid waste. In terms of population, the country's urban population in 1999 was 5.4 million, while by 2009 this population had grown to 12.5 million, with $3,233,788$ and 870,38 I residing in Nairobi and Mombasa respectively. This translates to 299,439 households in Mombasa and I, 128,693 households for Nairobi (Kenya National Bureau of Statistics., 2009). It is projected that by the year 2030 , about $50 \%$ of the Kenyan population will be living in urban centers (Government of the Republic of Kenya., 2007).

Waste generation has been increasing rapidly in Kenya and, due to the rapid urbanization, the current amount of waste (about 4 million tones/year) generated is expected to double by 2030 . However, the rise in waste generation has not been accompanied by an equivalent increase in the capacity of the relevant urban authorities to deal with this 2876 challenge of Solid Waste Management (SWM) (N. K. Gakungu and Gitau, 20/2). This situation in Kenya, according United Nations Environment Program (UNEP), is prototype of an economically developing nation, which tend to pay inadequate attention to SWM contrary to recent thinking on solid waste that views it as an asset that is generated in the urban areas, which should not be wasted as such through biogas, recycling, reusing, etc., all with possible revenue coming back to the communities (Charles Situma et al., 2007). In the main urban center, Nairobi, the Solid Waste that is well managed is much lower than the amount generated. The wide gap between the generation and collection means that unsafe disposal is rampant. It is estimated that about half (I500 tones/day) of solid waste generated are not collected.

Improper solid waste management (collection, transfer, treatment, recycling, resource recovery and disposal of solid waste), have been linked to a wide range of risks including the stagnation of economic development, the proliferation of disease, environmental degradation, a threat to climate change and ultimate impact on livelihoods. In particular, disastrous impacts of poor solid waste management within urban settlements particularly http://aps.journals.ac.za 
cities and big municipalities in relation to public health, the environment and ultimate adverse impact on the quality of life of all citizens have been severally identified (National Environment Management Authority, 20I4). Studies have shown that poor solid waste management is associated with childhood morbidity and mortality (Oloruntoba et al., 20l4, Reed and Mberu, 2014). Child morbidity impacts on children education which is a key tenet of human capital development. It also affects long term productively of children when they become adults. Given that reduction of childhood mortality and investment in education/human capital development are key tenets of demographic dividend, poor solid waste management would have a counter-productive impact on the realization of demographic dividend.

In response to the consistently increasing challenge of solid waste management, national and local governments have formulated and implemented several policy and program actions over the years. In this paper we examine policies that have guided SWM in Kenya over time. Because SWM and its effects cuts across various sectors and stakeholders, therefore to effectively address its challenges, policy integration, a seamless synchrony among policy provision, among and within the various sectors and stakeholders is essential. This concerns the management of cross-cutting issues in policy-making, implementation and evaluation (Persson, 2004).

In light of these, we examine the levels of integration within and among SWM policy frameworks in Kenya, particularly as they addressed associated health challenges among vulnerable populations in urban areas. More specifically, this study explored the coherence \& contradictions among SWM policies; and examined gaps and overlaps among key SWM policies. Moreover, this study seeks to identify strategies that would improve synergy and maximize efficiency in the implementation of SWM policies in Kenya.

\section{Literature Review \\ Solid waste}

Solid waste is a term commonly used to describe a heterogeneous non-liquid wastes generated mainly in urban areas. The nature of these wastes varies from region to region and the amount and characteristics of the solid waste produced in a region is a function of the living standard and lifestyle of the region's population, and the abundance and type of the region's natural resources. Solid waste in the developing nations generally has higher organic content than in industrialized countries as most farm products in developing countries are not processed. The characteristics of solid wastes also vary by geography. Countries located in the tropical zones have wastes with high concentrations of plant debris. Despite the differences in waste characteristics and composition, most waste invariably harbor hazardous agents such as medical pathogens, chemical residues and contaminants (United Nations Environmental Programme., 2005).

\section{Solid waste management}

Solid waste management is critical to any developingnation. Solid waste management involves five key components: generation, storage, collection,transportation and disposal (United Nations Environmental Programme.). At each level, different management actions are needed and in many instances the stakeholders involved vary. For effective and efficient management of solid wastes, the various components and stakeholders need to operate in an integrated manner. This need for integration calls for integrated approach of solid waste management. According to the US Environmental Protection Agency, Integrated Solid Waste Management (ISWM) is "a comprehensive waste prevention, recycling, composting, and disposal program. An effective ISWM system considers how to prevent, recycle, and manage solid waste in ways that most effectively protect human health and the environment (US Environmental Protection Agency., 2002)." ISWM is a framework for designing and implementing new waste management systems and for analyzing and optimizing existing systems. It is based on the concept that all elements of a waste management system should be considered together, since they are in fact interrelated and developments in one area frequently affect practices or activities in another area (Saeid et al., 20|4).

\section{Integration of solid waste management policies} Integrated solid waste management provides strategic approach to sustainable management of solid wastes covering all sources and all aspects: generation, segregation, transfer, sorting, treatment, recovery transfer, and disposal in such a manner that all steps relate and feed into each other, with emphasis on maximizing resource use efficiency An integrated and comprehensive solid waste management system requires well integrated policies and developing and enforcing integrated solid waste management regulations (Najm et al., 2002).

Despite the need for integrated policies for integrated solid waste management, evidence of levels and types of integration among different pieces of solid waste management policies is scanty. Analytic approaches to examine and present levels of integration among solid waste management policies are also limited. Therefore, this study is expected to contribute to filling this evidence gap through the 
analysis of integration of solid waste management policies in Kenya.

\section{Theoretical and Conceptual Models}

Policy integration is defined as "the management of cross-cutting issues in policy-making that transcend the boundaries of established policy fields, which often do not correspond to the institutional responsibilities of individual departments (Evert Meijers and Stead, 2004)."Policy integration may also be considered as the management of policy responsibility within a single organization or sector. Similarly, integrated policy-making could refer to both horizontal sectoral integration (between different departments and/or professions in public authorities) and vertical inter-governmental integration in policy-making (between different tiers of government), or combinations of both.

According to Underdal, the basic criteria for policies to be classified as integrated' are comprehensiveness, aggregation and consistency. Thus, an integrated policy is one where "all significant consequences of policy decisions are recognized as decision premises, where policy options are evaluated on the basis of their effects on some aggregate measure of utility, and where the different policy elements are in accord with each other (Underdal, 1980)."

A variety of other related terms such as policy coherence, cross-cutting policy-making, concerted decision-making, policy consistency, holistic government, joined-up government and, most especially, policy co-ordination are used to describe policy integration. Though others consider it as a dichotomy, Guy Peters argued that there is a continuum of policy integration and differentiation options, ranging from minimalist to maximalist (Peters Guy, 1998).

Hertin and Berkhout (200I) have identified four main means for policy integration: integrated departments, horizontal cooperation, and political leadership and sector integration strategies. Furthermore, they have suggested that these policy integration measures are expected to lead to four types of changes in policy systems: institutional agenda setting; building expertise and decisionmaking capacity in sectoral departments; wellfunctioning communication between various sectors; and policy learning (Hertin and F. Berkhout, 200I).

The criteria against which policy integration could be assessed also vary. In the area of environmental policy integration, the European Environment Agency's (EEA) criteria are much more concrete as compared to Underdal's criteria (European Environment Agency., 2004). Policy integration has been widely used in climate change and environmental policies (Ahmad, 2009, Gerard Mullally and Niall Dunphy, 20I5). It is also being highly promoted by the UN during and after the launch of the Sustainable Development Goals (UN Department of Economic and Social Affairs., 20I5). However, in the area of solid waste management, the landscape for policy integration is yet to be defined though the principles used in other fields could be well adapted.

\section{Methods}

\section{Data Sources and scope of the study}

Review of relevant policy frameworks on SWM in Kenya and its two major cities (Nairobi and Mombasa) was undertaken in order to have a broad understanding on key issues related to solid waste management policy architecture. The review addressed and captured information relating to the substantive areas relevant to policy integration. It has focused on broad areas such as cooperation, coordination and integrated policy-making.

This review has identified the following six categories sources of solid waste management policies.

I) External policies (global and regional policies) endorsed by the country

2) National laws that provide broad provisions (e.g. Constitution of Kenya)

3) Integrated policies that address many environmental issues (e.g. Environmental Management and Coordination act, A, Environmental Policy)

4) Sector-specific Acts (e.g. Public Health Act, Factories Act)

5) Issue-specific regulations (e.g. Water quality regulations, Waste management regulation)

6) Solid Waste Management (stand-alone) policies (e.g. National SWM Strategy)

\section{Definition of concepts}

Coherence: Consistency of policy process and content among various sectors of a government or within a specific sector of a government.

\section{Contradiction: Disagreements/conflicts} among different policy contents and/or their implementation within a sector or among sectors.

Gaps: Substantive areas of solid waste management expected to be addressed by policy frameworks but not adequately addressed within the existing policy architecture.

Overlaps: Substantive policy issues of solid waste management addressed by two or more policy frameworks. This may be necessary (affirmation) or unnecessary (duplication). 
Integration: The alignment between the provisions of various solid waste management policy contents and their implementation.

\section{Data abstraction}

Information from the selected policy documents was abstracted using pre-defined themes. The list of these themes and their description is shown in the following table.

Table I: Abstraction themes and their descriptions

\begin{tabular}{|l|l|}
\hline Abstraction theme & Description \\
\hline Policy domain & $\begin{array}{l}\text { The broader policy domain within which the respective policy content belongs } \\
\text { (e.g. environment, health, urban development, climate etc). }\end{array}$ \\
\hline Policy type & Whether the policy is a code, an Act, a regulation, a strategy, a plan, a bill etc. \\
\hline Institutional mechanism & $\begin{array}{l}\text { The major institutional mechanism leading the formulation of the policy and/or } \\
\text { the implementation of it. }\end{array}$ \\
\hline Focus of the policy & $\begin{array}{l}\text { The aspect/component of solid waste management addressed by the policy } \\
\text { framework }\end{array}$ \\
\hline Policy substance & $\begin{array}{l}\text { The policy content/text in the policy framework addressing solid waste } \\
\text { management }\end{array}$ \\
\hline
\end{tabular}

\section{Data analysis and synthesis}

This study employed a critical interpretive synthesis of the contents of the current national level SWM policies in Kenya, and city-specific policies for Nairobi and Mombasa. Selected policy documents were reviewed for pre-determined areas of integration generally and how they addressed health outcomes in particular. Nine types of integration were used in the analysis including Internal integration (within a policy framework), external integration (integration with other policies), horizontal integration (among sectorspecific policies), vertical integration (among levels of policies), and diagonal integration (between sectorspecific and compressive policies). Findings were summarized using narrative summaries and tables.

\section{Findings}

Macro-level (strategic) integration

At national level, the various SWM policy documents addressed different but thematically inter-related aspects of SWM. While the Penal Code makes it an offence to vitiate the environment, the Public Health Act focuses on prevention of nuisance that could affect health (Government of the Republic of Kenya., 1948, The Republic of Kenya., 1986). The Constitution of Kenya grants rights to protected environment along with the associated obligations to protect it (The Republic of Kenya., 2010). On the other hand, the Local Government Act and its successor the County Government Act have vested powers to local authorities to establish the necessary systems and procedures that are necessary to deal with SWM at local level (Government of the Republic of Kenya., 1963, The Republic of Kenya., 2012). In this regard, the four key policy documents are well synchronized as they address the inter-related aspects of SWM at national levels. This shows that integration at national level is ensured in two ways: I) complementarity (one policy framework complementing the other); and 2) Reinforcement (one policy framework re-enforcing the execution of the other).

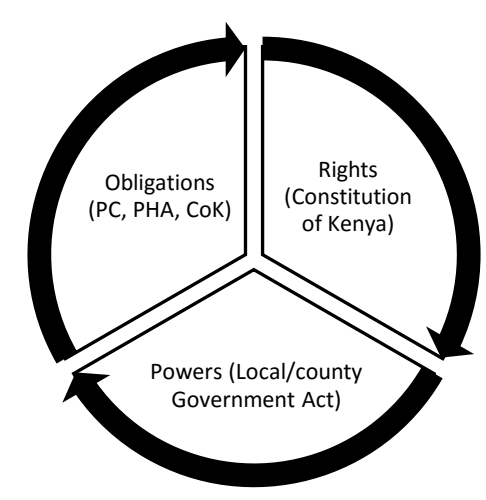

Figure I. Macro (national) level integration of SWM policies 
The Environmental Management and Coordination Act (EMCA), which was introduced in the presence of many of the sector-specific environmental provisions, was a more generic framework designed to facilitate a coordinated response to environmental management (The Republic of Kenya., 1999). Though it had the potential to integrate the fragmented sector-specific provisions, it was not aimed to supersede them. It was rather meant to reinforce them in to a better management model of the environment. Therefore, a clear overlap between EMCA and sector-specific policies, with no indication of policy hierarchy, was existing in the 2000s.

In line with the Constitution of Kenya, the National Environment Policy outlines responsibilities of the government - what the government will do in relation to creating a favorable ground for protecting the environment (Ministry of Environment, 20/3). The National Solid Waste Management strategy, which addresses only one core area of the National environment policy, aimed to establish a platform for action between stakeholders to systematically improve SWM (National Environment Management Authority., 2014). The integration between the Environment Policy and the Solid Waste Management Strategy is a vertical one - the policy outlined the core issues and the strategy formulated it in to courses of action. Though the national SWM strategy is national in its scope, it focused on flagship SWM projects in five main cities in Kenya. Besides, the strategy is more linked to the repealed EMCA and its regulations than to the National Environmental policy. This may be linked to the parallel timelines of the development of these two policy frameworks.

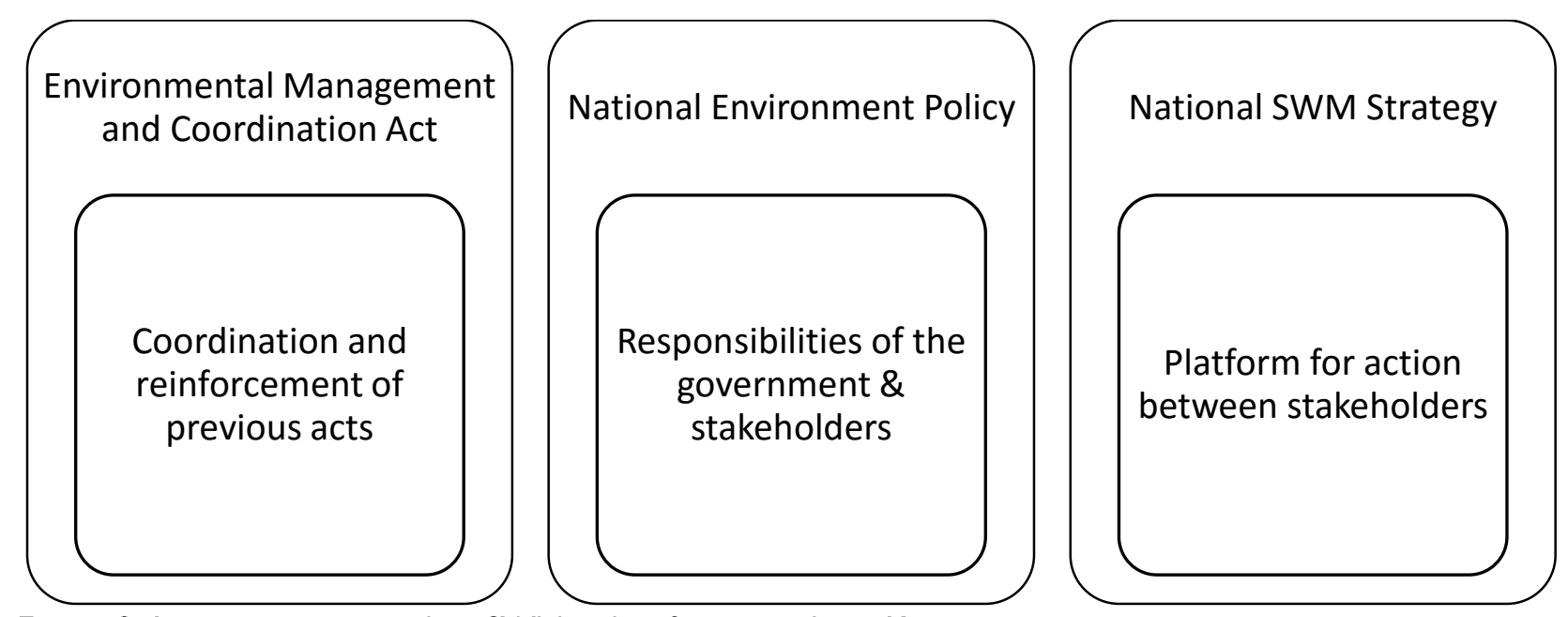

Figure 2. Integration among key SWM policy frameworks in Kenya

\section{Meso-level (Sectoral) Integration}

This form of integration is the harmonization among the sector specific Acts addressing issues related to SWM. The Factories Act, whose main focus is on First Aid rules in the factories to manage any health emergency at the scene, has provisions that require managers of factories to keep the environment clean and dispose any waste accordingly. The radiation protection act, which prohibits manufacturing, possessing, selling, disposing, importing and exporting any irradiating device or radioactive material that may have impacts on health, is entirely about dealing with radiation safety requirements. The building code details the handling of construction and demolition waste. The Food, Drug and Chemical Substances Act makes it an offence to use or dispose of any chemical substance in a manner likely to cause contamination of food or water for human consumption or in a manner liable to be injurious or dangerous to health.
Physical Planning act makes provision for development control and as such provided for waste disposal at designated sites only. Occupational Safety and Health Act deals with Chemical Safety and the securing of dangerous parts of machinery. Birth and Death Registration Act prohibits burying, cremating or otherwise disposing of body of deceased person without a permit. With a few overlaps among them, these sectoral-level policies address different SWM in a sector or a SWM issues across sectors.

Promoting health is the most pronounced integrating factor among four of the seven sectoral acts: The Factories Act; The Radiation Act; The Food, Drug and Chemical Substances Act; and Occupational Safety and Health Act. For the remaining three sectoral Acts - the Physical Planning Act, Building Code and Birth and Death Registration Act - the central focus is protecting the environment from debris and refuse and disposing them in the designated sites. 


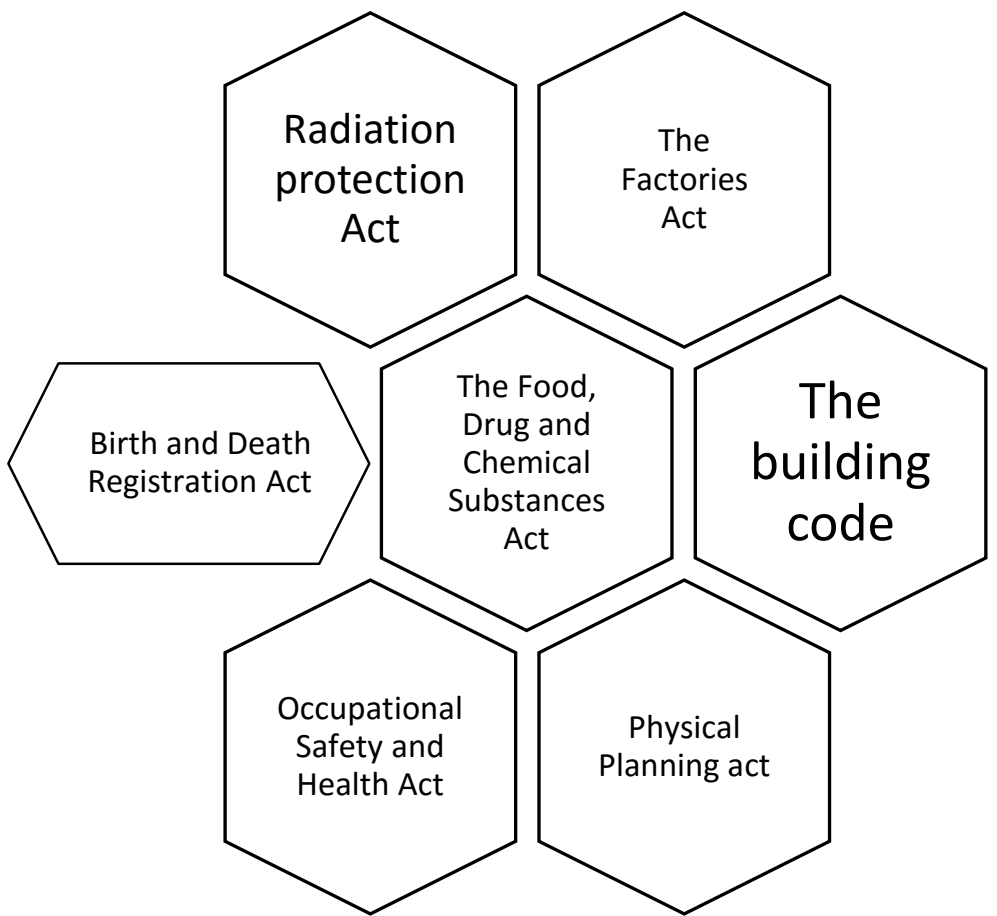

Figure 3. Meso (sectoral) integration of SWM policies in Kenya

Thematic level (Technical) integration

Following the endorsement of EMCA, several theme specific regulations were developed and enacted. Among these regulations were water quality regulation and air quality regulations that were developed to prevent water and air pollution, respectively (The Republic of Kenya., 2006, The Republic of Kenya., 2009a). The third regulation deals with prevention of noise and excessive vibration pollution (The Republic of Kenya., 2009b). Along with these were also regulations that address the disposal of municipal (household) wastes, controlled substances, and hazardous substances (The Republic of Kenya., 2007a, The Republic of Kenya., 2007b). The Environmental Impact assessment regulation establishes rules and procedures for licensing, conducting and reporting environmental impact assessment. Key aspects of EMCA, were addressed in these regulations. Although each of these has a component relevant to SWM, they addressed thematically dissimilar issues that fit in to the broader area of environmental management.

These regulations, all emerged from EMCA, and have protection of the environment as their most explicit driver of integration. The core objective was to protect the environment from pollution by different types of wastes and provide regulations for the proper disposal of these substances/wastes. Promotion of health and prevention of disease didn't receive direct attention in these regulations. In addition, the regulations haven't addressed several other types of wastes including industrial and medical (health-care) wastes though these were mentioned in water and air quality regulations. Moreover, there existed a healthcare waste management plan despite the absence of the theme in the general policies. In overall, the balance between segmentation and integration of SWM issues is blurred. 


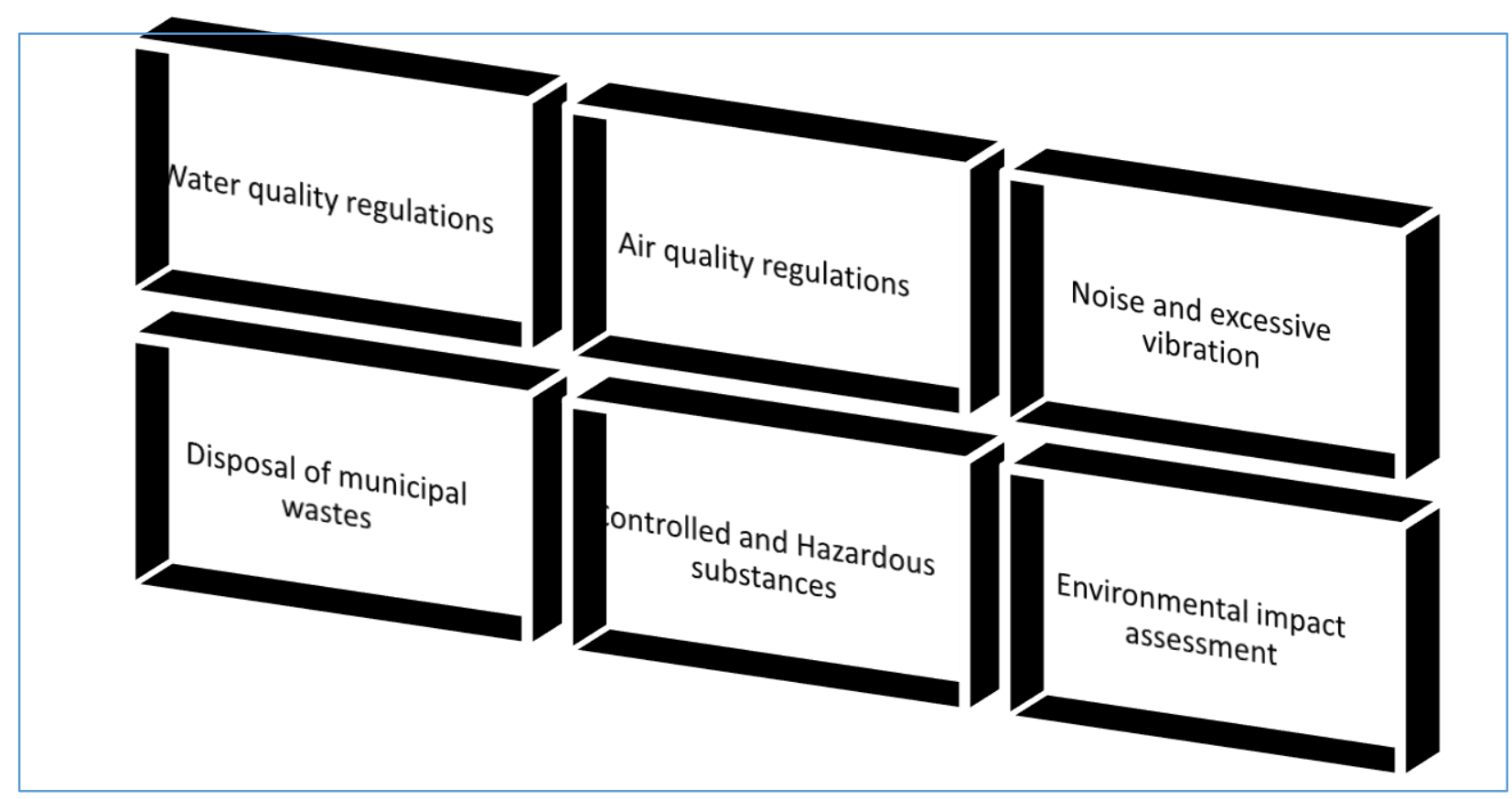

Figure 4: Thematic (Technical level integration)

Institutional level (Organizational) integration

The sector-wide SWM policies have been formulated and adopted by various sectors at national level. Though the coherence among these policies might have been ensured through the various policy processes leading to their refinement and final endorsement, there was no evidence of a national coordinating mechanism for their integrated implementation for years. However, at local governments, SWM roles converge and the need for a coordinating mechanism looks better addressed.

Integration within integrated policies (internal integration)

Two types of SWM integrated policies emerged in this review. The first type was sector-wide policy frameworks that also address the problem of solid waste management and the mitigation of its impacts. Health and environmental policies are the key examples among several others. The second type was environment-focused policies that address SWM among the proper management of other types of wastes (e.g. liquid wastes and human excreta wastes). While SWM is implied in health and environmental policies of Kenya, it emerged as an issue on its own (rather than a component along with the management of other types of wastes) after the EMCA.

Integration among different levels of SWM policies (vertical integration)

There are policies, strategies, acts and plans relevant to SWM at national level. There are also by-laws, and plans addressing SWM at county levels. Some sinstitutions could also have their own SWM policies, strategies and plans. The analysis of the harmony among these pieces of SWM policy frameworks revealed the lack of a coordinated approach to SWM policy making process. The timelines of the formulation and adoption of these policy frameworks at different levels don't concur. Even, the development of some of the policy frameworks was funded by external bodies. On the other hand, there is no evidence documented about the impacts of the previous policies, their strengths and weaknesses, when they were replaced by new ones. Integration along evolvement and devolvement lines is also found to be weak.

Integration between sector-specific and integrated policies (diagonal integration)

The integrated SWM policies were meant to coordinate the cross-cutting SWM issues across various sectors. As these also included sector-specific issues in order to provide guidance for specific sectors, this would be an area of alignment between sector-specific and integrated SWM policies. While management is expected at sector-level, technical leadership in SWM policies is expected from integrated policies. If the sector-specific and integrated SWM policies are well aligned, then SWM at sector level would be smooth. Sectors and Environmental coordination agencies need to work collaboratively towards this end. In the SWM policy evolution in Kenya, the overall focus has shifted both towards and away from integrated policies at many points in time and real coherence between the two 
needs attention in the future policy analysis and policy making efforts.

Integration of SWM policies with other key policies (external integration)

It is evident that SWM can affect and can be affected by other related policies including manufacturing, urban development, infrastructure and financial policies. In this review, we found out that some key policy frameworks gave greater emphasis to SWM. The two key examples are the Building Code and the Physical Planning Act that addressed SWM in a substantive manner. However, SWM is not mainstreamed in many other policy frameworks such as policies related to agriculture. Similarly, the development of SWM policies, strategies, and plans have taken into account key local contexts that would affect the implementation of these policies. The local government acts and city by-laws are examples of these. Despite these, the current SWM policies are loosely linked to other relevant policies in the country.

As reported elsewhere, the contents and evolution of SWM policies of Kenya reflect the influence of key global and regional environmental policies (Tilahun Nigatu et al., 2016). Accordingly, the priorities of current SWM policies of Kenya have a base on key regional and global priorities.

Integration between policies and implementation (translational integration)

This policy review has revealed that there are good SWM policy provisions that are in place in Kenya. However, the problem of poor solid waste management is still a major challenge and is expected to expand its scale with the rapid urbanization in the country. This has demonstrated that the gap between policy and action is the major problem. Preliminary observations regarding the causes of this policypractice gap includes the following:

1) The fact that SWM policies and their implementation mechanisms didn't fully consider the ever changing dynamics of solid waste management realities and are not substantiated with evidence of what works and what doesn't work.

2) Policy making processes highly driven by government in a top-down approach with limited participation and ownership by the public and private sectors.

3) Insufficient institutional capacity and resources to streamline and enforce the implementation of recommended solid waste management procedures and practices.

4) Weak political commitment, use of solid wastes as main source of informal businesses, and corruption.
5) The deep-rooted attitude of considering solid waste as a problem than a resource that could be recycled and used; and lack of infrastructure to recycle solid wastes.

\section{Discussion}

\section{Summary of the evidence}

At macro-level, the dimensions of integration among the core SWM polices were temporal (one repealed when the other is enacted), functional (addressing different but related functions) and hierarchical (one superseding/guiding the other). At meso-level horizontal integration of sector-specific acts seems to follow a pattern of integration by departmentalization. However, our analysis has shown that horizontal integration at thematic level is by specification of the regulations in priority areas in the environmental management. At local government level, SWM roles converge and the need for a coordinating mechanism looks better addressed. Integration along evolvement and devolvement lines is also found to be weak. In the SWM policy evolution in Kenya, the overall focus has shifted towards integration at one time and away from integrated policies at another time and real coherence between the two needs attention in the future policy analysis and policy making efforts.

\section{What do the findings mean?}

While the policy provisions are well aligned with the key priorities, there is no strong evidence supporting adequate level of integration among the different policy implementation efforts. The policy goals aspire for zero waste but empirical studies have revealed that the problem of solid waste management is significant in many urban areas of Kenya (Henry et al., 2006). In Coastal towns, which are tourist attraction sites, even though the legislation is in place, there were inadequate enforcement plans in place to ensure compliance (Monyoncho, 20I3). Though, the lack of policy integration can't be considered as the sole cause of the gap between SWM policies and their implementation, it would be among the various factors. With the increase in urbanization and associated waste generation, this remains a challenge in many African urban settings (Parrot et al., 2009, Bassey et al., 2006).

\section{Implications for policy, practice and research}

The findings of this policy review have important implications for policy, practice and research. Firstly, implementation of current policies and development of future policies need to pay adequate attention to policy integration at all levels, which is critical for effective and efficient response to the problem of solid waste management in Kenya and other African 
countries. Secondly, solid waste management practices are required to use an integrated approach between the different stages and the various stakeholders. The current level of policy integration doesn't imply the absence of opportunities for integration at implementation. Thirdly, more research is needed to illustrate why the current level of policy integration has become a reality and how SWM policy integration could be improved in a sustainable manner in the future.

\section{Limitations}

This analysis was based on review of policy documents and didn't consider the policy making processes and procedures involved in the development of the policies. Integration was seen from the perspective of coherence among policy provisions. Thus, the findings may not necessarily reflect the integration in the implementation of SWM policies. Moreover, the findings of the analysis are context-loaded and interpretation without due consideration of the specific policy frameworks.

\section{Conclusions and Recommendations}

Analysis of integration of SWM policies in Kenya has revealed that extent of integration differs across different axis of policy development, evolvement and devolvement. At macro-level, integration of policy contents looks better but coordination mechanism for implementation is not clear. At Meso-level, the balance between segmentation, integration and devolvement is contentious. It is clear that this would result in contradictions in implementations of SWM policies.

The roles of specific and integrated SWM policies are not well differentiated. We anticipated that specific policies will focus on management issues while integrated policies focus on technical leadership in policy making, implementation and evaluation. However, this analysis has shown that there is a significant overlap between these two forms of SWM policies in Kenya.

Along with the acknowledgement and reaffirmation of other policies, SWM policies in Kenya, especially the environmental policy and solid waste management strategy, are well aligned with regional and global policies relevant to environment and health including the Rio Declaration. Overall, existing solid waste management policies clearly state the policy directions in terms of the required outcomes. But explicit articulation of policy strategies and implementation mechanisms is insufficient.

Based on the findings of the review, we forward the following four suggestions. First, there is need for a clear coordination mechanism for policy making, implementation and evaluation. This mechanism can ensure alignment among the different provisions and synergy in their implementation. Next, enhancing institutional capacity (infrastructural, financial and human resources) of key actors in the government sector is needed for successful implementation of the policies. Further, the citation and referencing styles of policy frameworks need to be improved so that analysis of influence of global and regional policies on the national policies can be less challenging. Finally, further research is needed to disentangle the bottlenecks and their detailed attributes that affect the implementation of SWM policies in Kenya

\section{Acknowledgement}

We would like to extend our acknowledgement to ESRC and DFID for their financial support to this study through the Urban ARK Programme. We also extend our appreciation to the late Elijah Agevi who had provided essential inputs in to this study.

\section{References}

Ahmad, I. H. 2009. Climate Policy Integration: Towards Operationalization. In: AFFAIRS, D. O. E. A. S. (ed.). New York: United Nations

Bassey, B. E., Benka-Coker, M. O. \& Aluyi, H. S. 2006. Characterization and Management of Solid Medical Wastes in the Federal Capital Territory, Abuja Nigeria. Afr Health Sci, 6, 58-63.

Charles Situma, Ashbindu Singh, Charles Sebukeera, Henry Ndede, Christopher O. Ambala, Michael Mwangi, Eugene Apindi Ochieng, Erick Khamala, Ambrose Oroda, Catherine Hallmich \& Lund, G. H. 2007. Nairobi and its Envrioment. In: JANE BARR \& SHISANYA, C. (eds.) Kenya Atlas of Our changing Environment. Kenya: UNEP.

European Environment AgencY. 2004. Environmental Policy Integration - Paper I: State of the Art Review. Copenhagen: EEA.

Evert Meijers \& Stead, D. 2004. Policy integration: what does it mean and how can it be achieved? A multi-disciplinary review. Human Dimensions of Global Environmental Change: Greening of Policies - Interlinkages and Policy Integration. Berlin, Germany.

Gerard Mullally \& Niall Dunphy 2015. State of Play Review of Environmental Policy Integration Literature. In: National Economic And Social Council (Nesc) (ed.). Ireland: National Economic and Social Council (NESC),

Government Of The Republic Of Kenya. 1948. Penal Code: An Act of Parliament to establish a code of criminal law. Nairobi, Kenya: GoK.

Government Of The Republic Of Kenya. 1963. The Local Government Act: Chapter 265. Nairobi, Kenya: National Council for Law Reporting 
Government Of The Republic Of Kenya. 2007. Kenya Vision 2030. In: CENSUS, K. P. A. H. (ed.). Nairobi, kenya: Kenya Population and Housing Census.

Henry, R. K., Yongsheng, Z. \& Jun, D. 2006. Municipal solid waste management challenges in developing countries--Kenyan case study. Waste Manag, 26, 92- 100.

Hertin, J. \& F. Berkhout 200I. Ecological modernisation and EU environmental policy integration: SPRU Electronic Working Paper Series Paper no. 72. Brighton: University of Sussex.

Kenya National Bureau Of Statistics. 2009. Kenya Population and Housing Census Report Kenya.

Ministry Of Environment, W. A. N. R. 20I3. National Environment Policy Nairobi, kenya: Ministry of Environment, Water and Natural Resources.

Monyoncho, G. O. 2013. Solid Waste Management in Urban Areas Kenya: A case study of Lamu Town. PGD, University of Nairobi.

N. K. Gakungu \& Gitau, A. N. 2012. Solid waste management in kenya: A case study of

public technical training institutions ICASTOR Journal of Engineering 5, I 27-I 38.

Najm, M. A., El-Fadel, M., Ayoub, G., El-Taha, M. \& Al-Awar, F. 2002. An optimisation model for regional integrated solid waste management II. Model application and sensitivity analyses. Waste Manag Res, 20, 46-54.

National Environment Management Authority. 2014. National Solid Waste Management Strategy Nairobi, kenya: National Environment Management Authority.

Oloruntoba, E. O., Folarin, T. B. \& Ayede, A. I. 2014. Hygiene and sanitation risk factors of diarrhoeal disease among under-five children in Ibadan, Nigeria. Afr Health Sci, I4, I00 I-I I.

Parrot, L., Sotamenou, J. \& Dia, B. K. 2009. Municipal solid waste management in Africa: strategies and livelihoods in Yaounde, Cameroon. Waste Manag, 29, 986-95.

PERSSON, A. 2004. Environmental Policy Integration: An Introduction. In: SUSTAINABILITY, P. P. I. F. (ed.). Stockholm: Stockholm Environment Institute

Peters Guy 1998. Managing horizontal government: The politics of coordination. Research Paper No. 21. Ottawa: Canadian Centre for Management Development.

Reed, H. E. \& Mberu, B. U. 20|4. Capitalizing on Nigeria's demographic dividend: reaping the benefits and diminishing the burdens. Etude Popul Afr, 27, 319-330.

Saeid, N., Roudbari, A. \& Yaghmaeian, K. 2014. Design and implementation of integrated solid http://aps.journals.ac.za wastes management pattern in industrial zones, case study of Shahroud, Iran. J Environ Health Sci Eng, 12, 32.

The Republic of Kenya. 1986. Public Health Act: Chapter 242. Nairobi, Kenya: National Council for Law Reporting.

The Republic of Kenya. 1999. Environmental Management And Coordination Act: Chapter 387. Nairobi, kenya: National Council for Law Reporting.

The Republic of Kenya. 2006. The environmental management and co-ordination (water quality) regulations. Nairobi, Kenya

The Republic of Kenya. 2007a. The environmental management and co-ordination (controlled substances) regulations. Nairobi, Kenya

The Republic of Kenya. 2007b. The Environmental Management and Coordination (Hazardous Substances) Regulations. Nairobi, Kenya

The Republic of Kenya. 2009a. The Environmental management and coordination (Air Quality) regulations. Nairobi, Kenya

The Republic of Kenya. 2009b. The Environmental Management and Coordination (Noise and Excessive Vibration Pollution) regulations. Nairobi, Kenya

The Republic of Kenya. 2010. Constitution of Kenya. Nairobi, kenya: National Council for Law Reporting.

The Republic of Kenya. 2012. The County Goverment Act Nairobi, Kenya

Tilahun Nigatu, H., Blessing, M. \& Ziraba, A. 2016. Evolution of Solid Waste Management Policy landscape in Kenya: Analysis of Evolvement of policy priorities and strategies. United Kingdom: Urban ARK.

Un Department Of Economic And Social Affairs. 2015. Policy integration in government in pursuit of the sustainable development goals: Report of the expert group meeting held on 28 and 29 January 2015 at United Nations Headquarters New York.

Underdal, A. 1980. Integrated marine policy: What? Why? How? Marine Policy, I59-169.

United Nations Environmental Programme. Integrated Solid Waste Management. OSAKA JAPAN: International Environmental Technology Centre (IETC).

United Nations Environmental Programme. 2005. Solid Waste Managment UNEP.

US Environmental Protection Agency. 2002. What Is Integrated Solid Waste Management? : United States Environmental Protection Agency. 